\title{
Imaging hNET Reporter Gene Expression with ${ }^{124}$ I-MIBG
}

\author{
Maxim A. Moroz*1, Inna Serganova*1, Pat Zanzonico², Ludmila Ageyeva ${ }^{1}$, Tatiana Beresten ${ }^{1}$, Ekaterina Dyomina ${ }^{1}$, \\ Eva Burnazi ${ }^{3}$, Ronald D. Finn ${ }^{3-5}$, Michael Doubrovin ${ }^{1}$, and Ronald G. Blasberg ${ }^{1,4,5}$ \\ ${ }^{I}$ Department of Neurology, Memorial Sloan-Kettering Cancer Center, New York, New York; ${ }^{2}$ Department of Medical Physics, Memorial \\ Sloan-Kettering Cancer Center, New York, New York; ${ }^{3}$ Cyclotron and Radiochemistry Core Facility, Memorial Sloan-Kettering Cancer \\ Center, New York, New York; ${ }^{4}$ Department of Radiology, Memorial Sloan-Kettering Cancer Center, New York, New York; and ${ }^{5}$ Memorial \\ Hospital Molecular Pharmacology and Chemistry Program, Memorial Sloan-Kettering Cancer Center, New York, New York
}

The norepinephrine transporter (NET) has recently been suggested as a useful reporter gene. We have extended this effort by constructing an internal ribosomal entry site (IRES)-linked hNET-green fluorescent protein (GFP) hybrid reporter gene for both nuclear and optical imaging. Methods: A retroviral vector pQCXhNET-IRES-GFP was constructed and used to generate several reporter cell lines and xenografts. Transduced cells were sorted by fluorescence-activated cell sorting based on GFP expression and used for both in vitro and in vivo imaging studies. Results: The transduced reporter cells accumulated ${ }^{123} \mid$ - or ${ }^{124} \mid-$ labeled metaiodobenzylguanidine (MIBG) to high levels compared with the wild-type parent cell lines. Differences in MIBG accumulation between cell lines were primarily due to differences in influx $\left(K_{1}\right)$ rather than efflux $\left(k_{2}\right)$. The estimated MIBG distribution volumes $\left(V_{d}\right)$ for transduced Jurkat, C6, and COS-7 cells were $572 \pm$ $13,754 \pm 25$, and 1,556 $\pm 38 \mathrm{~mL} / \mathrm{g}$, respectively. A correlation between radiotracer accumulation $\left(\mathrm{K}_{1}\right)$ and GFP fluorescence intensity was also demonstrated. Sequential imaging studies of mice bearing $\mathrm{PQCXhNET-IRES-GFP}$ transduced and wild-type C6 xenografts demonstrated several advantages of ${ }^{124}$ I-MIBG small-animal PET compared with ${ }^{123} \mathrm{I}-\mathrm{MIBG} \gamma$-camera/SPECT. This was primarily due to the longer half-life of ${ }^{124} \mid$ and to the retention and slow clearance (half-time, $63 \pm 6 \mathrm{~h}$ ) of MIBG from transduced xenografts compared with that from wild-type xenografts (half-time, $12 \pm 1 \mathrm{~h}$ ) and other organs (half-time, 2.6-21 h). Very high radioactivity ratios were observed at later imaging times; at $73 \mathrm{~h}$ after ${ }^{124}$ I-MIBG injection, the C6/hNET-IRES-GFP xenograftto-muscle ratio was $293 \pm 48$ whereas the $\mathrm{C} 6$ xenograft-to-muscle ratio was $0.71 \pm 0.19$. Conclusion: These studies demonstrate the potential for a wider application of hNET reporter imaging and the future translation to patient studies using radiopharmaceuticals that are currently available for both SPECT and PET.

Key Words: human norepinephrine transporter; ${ }^{124}$ I-MIBG; ${ }^{123}$ |MIBG; PET; $\gamma$-camera; SPECT; molecular imaging; reporter gene

J Nucl Med 2007; 48:827-836

DOI: 10.2967/jnumed.106.037812

Received Nov. 1, 2006; revision accepted Jan. 20, 2007.

For correspondence or reprints contact: Ronald G. Blasberg, MD, Departments of Neurology and Radiology, MH (Box 52), Molecular Pharmacology and Chemistry Program, SKI, Memorial Sloan-Kettering Cancer Center, 1275 York Ave., New York, New York 10021.

E-mail: blasberg@neuro1.mskcc.org

${ }^{*}$ Contributed equally to this work.

COPYRIGHT @ 2007 by the Society of Nuclear Medicine, Inc.
$\mathbf{T}$ he norepinephrine transporter (NET) functions as a rapid norepinephrine reuptake system located at or near presynaptic terminals and terminates noradrenergic signaling by rapid reuptake of neuronally released norepinephrine. In this capacity, NET provides a finely regulated mechanism for noradrenergic-mediated behavioral and physiologic effects, including mood, depression, cognition, and regulation of feeding patterns, blood pressure, and heart rate. Human NET (hNET) is a transmembrane protein (617 amino acids) that mediates the transport of norepinephrine, dopamine, and epinephrine across the cell membrane (1). Human, bovine, rat, and mouse NET complementary DNAs (cDNAs) have been cloned $(1,2)$. In humans, NET is encoded by a single gene of 14 exons and 13 introns. NET protein belongs to a family of $\mathrm{Na}^{+} / \mathrm{Cl}^{-}$-dependent transporters that have highly conserved hydrophobic amino acid sequences (12 or 13 transmembrane domains), with less conservation at their amino and carboxyl ends. NET is considered to be a homo-oligomer complex, where $\mathrm{Na}^{+}$and $\mathrm{Cl}^{-}$ions provide an inward electrochemical gradient and adenosine triphosphate/adenosine triphosphatase are critical elements for neurotransmitter accumulation (2).

The expression of NET in mammals is almost exclusively restricted to the central and peripheral sympathetic nervous system (3). Because of its localized expression in the body, the hNET has recently been suggested as a human reporter gene (4-6). Advantages of hNET as a human reporter gene include the availability and established efficacy of several different radiopharmaceuticals for clinical imaging of endogenous hNET expression in neuroendocrine tumors and for imaging altered sympathetic enervation of the heart in various cardiac disease states $(7,8)$. An extensive 20-y history of $\gamma$-camera/SPECT of hNET expression exists with ${ }^{123} \mathrm{I}-$ or ${ }^{131} \mathrm{I}$-labeled metaiodobenzylguanidine (MIBG) $(9,10)$, and a less extensive 16-y history of PET exists with ${ }^{11} \mathrm{C}$-labeled hydroxyephedrine (HED) (11). Efforts to develop new and better radiolabeled norepinephrine analogs continue, particularly for imaging the hNET in brain, where the blood-brain barrier limits the access of currently available radiotracers, including MIBG and HED (12). 
Because NET is a cell-surface transporter and binding of the ligand occurs at the cell membrane, radiopharmaceutical delivery to systemic tissues is rapid and determined by equilibration between blood and extracellular fluid. The signal generated by radioligand accumulation is "transport-amplified" and, therefore, substantially greater than that due to binding to the transporter alone. The human origin of the hNET protein is also important, as it is unlikely to generate an immune response. This is a considerable advantage and facilitates the design of reporter systems for application in long-term human subjects. Currently, the most widely used radionuclidebased reporter gene in both animal and patient studies is the herpes simplex virus-type 1 thymidine kinase gene (HSV1-tk) $(13,14)$ and the sr39 variant (HSV1-tk ${ }_{\text {sr39 }}$ ) $(15,16)$. Although HSV1-tk has been used widely as a suicide gene in many anticancer research studies and documented HSV1-tk immunogenicity is sparse (17), potential risks for long-term expression of this transgene remain a concern, especially for nonsuicide gene applications.

Other human genes have been proposed and developed as reporter genes; they include cell membrane transporter genes, such as the human sodium iodide symporter (hNIS) (18), as well as genes that encode for cell-surface and intracellular receptors, including the human somatostatin receptor subtype-2 (hSSTR2) (19) and the dopamine D2 (hD2R) receptor (20). Background expression of the hNIS reporter could be a problem; endogenous hNIS expression is at very high levels in thyrocytes and stomach but is lower in mammary, salivary, and lacrimal glands (21). The expression of the 2 receptors is more limited within the body; $\mathrm{hD} 2 \mathrm{R}$ expression is largely limited to the striatal-nigral system of the brain, and hSSTR2 expression is largely limited to carcinoid tumors. Both transporters and receptors have clinically approved radiopharmaceuticals for imaging: ${ }^{123}$ I- or ${ }^{131}$ I-iodide $(9,10),{ }^{111}$ In-DTPA-octreotide (DTPA is diethylenetriaminepentaacetic acid) and 3-( $2^{\prime}-{ }^{18} \mathrm{~F}$-fluoroethyl)spiperone (FESP) (22), respectively.

To further explore hNET as a potential human reporter gene, we constructed a constitutively expressing dualreporter retroviral vector, pQCX-hNET linked with green fluorescent protein (GFP) through internal ribosome entry site (IRES), and used this vector to transduce 3 different cell lines. In vitro uptake studies using radiolabeled MIBG were performed in transduced and wild-type cells, and the resulting data were analyzed kinetically to yield estimates of MIBG influx $\left(\mathrm{K}_{1}\right)$, efflux $\left(\mathrm{k}_{2}\right)$, and volume of distribution $\left(\mathrm{V}_{\mathrm{d}}\right)$. The focus of our study, however, was to compare ${ }^{124} \mathrm{I}-$ MIBG PET with ${ }^{123}$ I-MIBG $\gamma$-camera and SPECT of hNET expression in the same animals, bearing xenografts that were generated from stably transduced and wild-type cell lines. These comparative studies demonstrated the advantages of ${ }^{124}$ I-MIBG PET and suggest that the optimal time for ${ }^{124} \mathrm{I}-\mathrm{MIBG}$ PET is late, $\sim 48-72 \mathrm{~h}$ in mice, when tissue background radioactivity is low.

\section{MATERIALS AND METHODS}

\section{Generation of pQCXhNET-IRES-GFP Retroviral Vector} and Transduction of Tumor Cells

The pQCXhNET-IRES-GFP retroviral vector bearing the hNET and GFP genes separated by an IRES was developed by substitution of hNET for the hNIS gene in the previously developed vector pQCXhNIS-IRES-GFP (23). The full-length human norepinephrine transporter (hNET) cDNA was obtained by polymerase chain reaction using primers with flanking NotI $\left(5^{\prime}\right)$ and BamHI ( $3^{\prime}$ ) restriction sites. As a template, we used the retroviral plasmid M48EF1a/II-hNETIVSIRES-hyg kindly provided by Dr. Uwe Haberkorn (1). The resulting retroviral plasmid contains a constitutive cytomegalovirus promoter, which drives the expression of the hNET and IRES-linked GFP reporter genes (Fig. 1A).

SK-N-SH, C6, COS-7, and Jurkat cell lines were obtained from American Type Culture Collection. Cells were transduced with the pQCXhNET-IRES-GFP retroviral vector as previously described (24). GFP expression in transduced tumor cells was visualized by fluorescence microscopy using a Nikon Eclipse T-100. After transduction, the cells were expanded in culture for several days and prepared for subsequent fluorescence-activated cell sorting (FACS) analysis and cell sorting as previously described (25).

\section{MIBG Synthesis}

The ${ }^{123}$ I-MIBG was obtained from MDS Nordion (Canada). The average radiochemical purity was in excess of $97 \%$ (determined by MDS Nordion using the Sep-Pak cartridge [Waters Corp.] method), and the specific activity was $\sim 322 \mathrm{MBq} / \mu \mathrm{mol}$ $(8.7 \mathrm{mCi} / \mu \mathrm{mol})$ according to the vendor. ${ }^{124} \mathrm{I}-\mathrm{MIBG}$ was prepared using minor modifications to the recently reported nucleophilic isotopic exchange method (26). To a reaction vial containing $2 \mathrm{mg}$ of MIBG-hemisulfate is added $0.5 \mathrm{mg}$ of $\mathrm{SnSO}_{4}, 5 \mathrm{mg}$ of $2,5-$ dihydroxybenzoic acid, $11 \mathrm{mg}$ of citric acid, and $0.1 \mathrm{mg} \mathrm{CuSO}$, and at the end is added no-carrier-added $\mathrm{Na}^{124} \mathrm{I}$ to an end volume of $0.8 \mathrm{~mL}$. The reaction mixture is flushed with $\mathrm{N}_{2}$ and heated at $130^{\circ} \mathrm{C}$ for $30 \mathrm{~min}$. On cooling, the mixture is passed through a C-18 Sep-Pak cartridge and the product is eluted with absolute ethanol. The final product is passed through a $0.22-\mu \mathrm{m}$ filter into a sterile vial. The radiochemical purity of the final product was $>95 \%$, with an overall yield of $>80 \%$; the specific activity was $18.5 \pm 5.2 \mathrm{MBq} / \mu \mathrm{mol}(0.5 \pm 0.14 \mathrm{mCi} / \mu \mathrm{mol})$. The maximum specific activity (no-carrier-added synthesis) for ${ }^{123} \mathrm{I}-$ and ${ }^{124} \mathrm{I}-$ labeled compounds is 8.9 and $1.2 \mathrm{TBq} / \mu \mathrm{mol}(241$ and $33 \mathrm{Ci} /$ $\mu \mathrm{mol})$, respectively, due to the 7.4-fold difference in the rate of radioactive decay of the 2 isotopes.

\section{Radiotracer Assay for hNET Expression In Vitro}

Radiotracer MIBG uptake studies were performed in C6/hNETIRES-GFP, COS-7/hNET-IRES-GFP, and Jurkat cells/hNETIRES-GFP and in nontransduced wild-type cells using previously described methods (23). Briefly, cells $\left(5 \times 10^{4} / \mathrm{mL} \times 20 \mathrm{~mL}\right)$ were seeded onto $15-\mathrm{cm}$ dishes. After a $24-\mathrm{h}$ incubation period at $37^{\circ} \mathrm{C}$ with $5 \% \mathrm{CO}_{2}$, the medium was aspirated and the cells were washed with phosphate-buffered saline ( $\mathrm{pH}$ 7.4). MIBG uptake was initiated by adding $15 \mathrm{~mL}$ of Dulbecco's modified Eagle medium containing $0.0037 \mathrm{MBq} / \mathrm{mL}(0.1 \mu \mathrm{Ci} / \mathrm{mL}){ }^{124} \mathrm{I}-\mathrm{MIBG}$ or 123I-MIBG. Cells were harvested after a 15- to 240-min incubation period, and the activity ratio in the cell pellet and medium was measured in a Packard $\gamma$-counter (United Technologies). All experiments were performed in duplicate and repeated at least twice. 


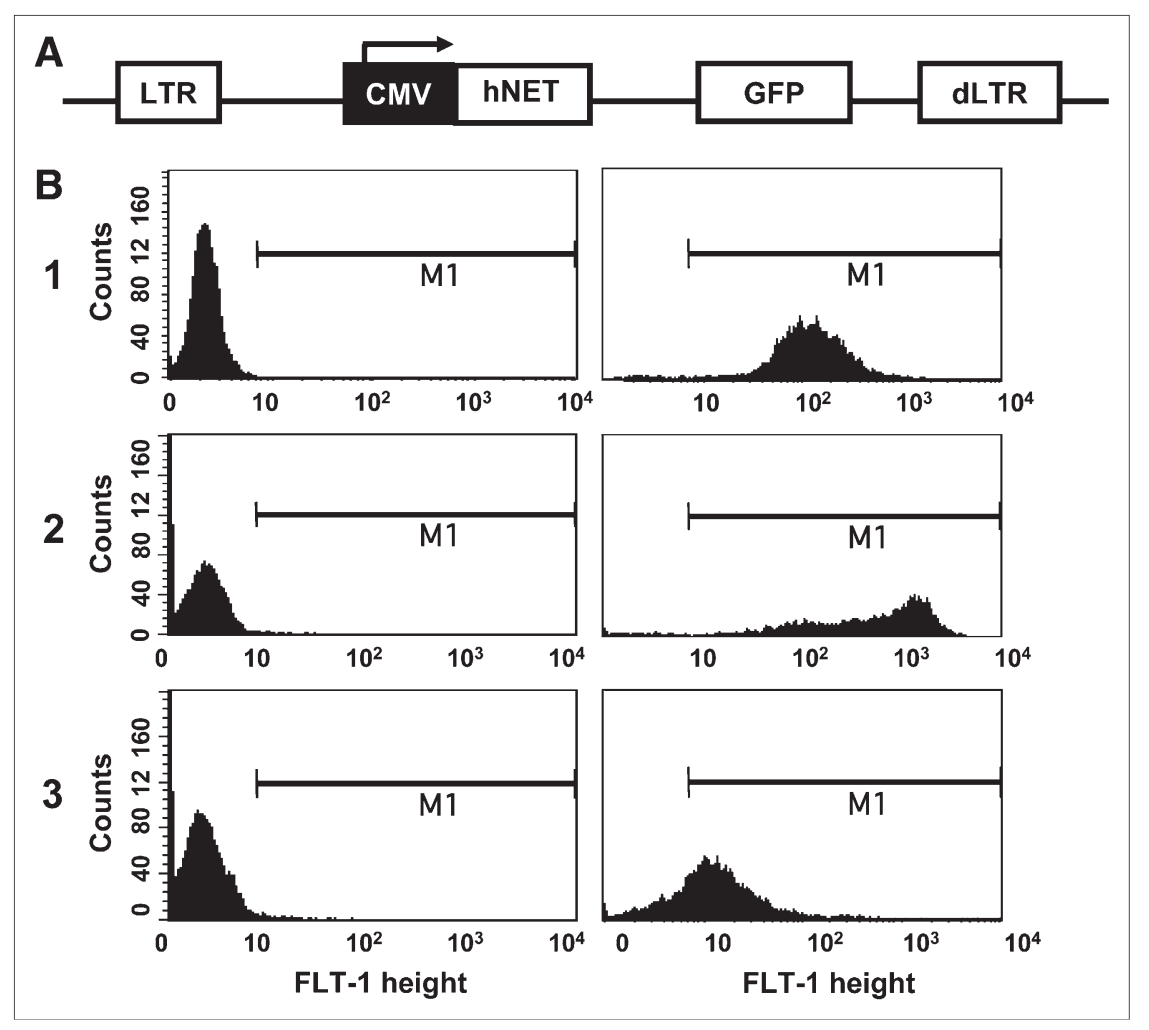

FIGURE 1. Development of reporter system and reporter cells. (A) Structure of pQcmv-hNET-IRES-GFP vector. (B) Fluorescence-activated cell sorting (FACS) analyses of C6 (1), COS-7 (2), and Jurkat (3) wild-type and pQcmv-hNETIRES-GFP transduced cells after FACS. $\mathrm{LTR}=$ long terminal repeat; $\mathrm{dLTR}=\mathrm{LTR}$ with deleted promoter sequence; $\mathrm{M} 1=$ range of GFP expression; FLT-1 = fluorescent channel 1.
The uptake profiles were fitted to a 1-compartment model to estimate the influx rate constant $\left(\mathrm{K}_{1}, \mathrm{~mL}\right.$ medium $/ \mathrm{g}$ cells $\left./ \mathrm{min}\right)$, the efflux rate constant $\left(\mathrm{k}_{2}, \min ^{-1}\right)$, and the volume of distribution $\left(\mathrm{V}_{\mathrm{d}}, \mathrm{mL}\right.$ medium/g cells). The fitting was performed using KaleidaGraph (Synergy Software) (version 3.6.4).

\section{Immunoblot Analysis}

To evaluate the level of hNET protein expression in reporter cells (C6, Jurkat, and COS-7/hNET-IRES-GFP), positive control cell line (SK-N-SH wild-type), and wild-type cells, immunoblot analysis was performed. A purified mouse antibody against hNET (NET17-1; Mab Tech Inc.) was used at a final dilution of 1:500, and a 12-h incubation at $+4^{\circ} \mathrm{C}$ was performed. The secondary antibody (peroxidase-conjugated antimouse IgG; Vector Laboratories Inc.) exposure was for $1 \mathrm{~h}$ at a 1:2,000 dilution. Peroxidase-bound protein bands were visualized using the electrochemoluminescence method (Amersham Pharmacia Biotech).

\section{In Vivo Imaging}

Two cohorts of animals were studied. Both cohorts included 6 athymic rnu/rnu mice (National Cancer Institute) bearing C6/ hNET-IRES-GFP and C6 wild-type xenografts in opposite shoulders. All animal studies were performed under a Memorial SloanKettering Cancer Center protocol approved by the Institutional Animal Care and Utilization Committee. The mice were anesthetized by inhalation of isoflurane/oxygen. After the studies all animals were sacrificed by $\mathrm{CO}_{2}$ inhalation.

\section{3/-MIBG $\gamma$-Camera/SPECT}

Each animal was injected intravenously with $11.1 \mathrm{MBq}(300$ $\mu \mathrm{Ci})$ of ${ }^{123} \mathrm{I}-\mathrm{MIBG}$ and imaged on an X-SPECT dedicated small-animal $\gamma$-camera SPECT/CT scanner (Gamma Medica). A photopeak energy window of 143-175 keV and a low-energy, high-resolution (LEHR) parallel-hole collimator was used to acquire the ${ }^{123}$ I images. Planar dynamic imaging, at 1 frame per minute, was performed immediately after ${ }^{123}$ I-MIBG injection over $30 \mathrm{~min}$. The full width half maximum (FWHM) spatial resolution was $\sim 7 \mathrm{~mm}$ (based on imaging of ${ }^{99 \mathrm{~m}} \mathrm{Tc}$ line sources in air at a source-to-detector distance of $10 \mathrm{~cm}$ ). A combined set of static planar and SPECT (64 projection images [at 32 azimuths of the dual-detector X-SPECT system] at $1 \mathrm{~min}$ per image) images was acquired at 4 and $24 \mathrm{~h}$ (cohort 1 ) and at 4,24 , and $48 \mathrm{~h}$ (cohort 2). Transverse images were reconstructed by filtered backprojection.

\section{I-MIBG microPET Imaging}

The first cohort of mice (described above) was also imaged sequentially over $72 \mathrm{~h}$, after intravenous injection of $7.4 \mathrm{MBq}$ $(200 \mu \mathrm{Ci})$ of ${ }^{124} \mathrm{I}-\mathrm{MIBG}$, using a Focus 120 microPET dedicated small-animal PET scanner (Siemens Medical Solutions USA, Inc.). ${ }^{124} \mathrm{I}-\mathrm{MIBG}$ was injected $48 \mathrm{~h}$ after ${ }^{123} \mathrm{I}-\mathrm{MIBG}$ was administered; PET before ${ }^{124} \mathrm{I}-\mathrm{MIBG}$ injection showed only background activity, demonstrating that residue ${ }^{123}$ I radioactivity was not visualized by the Focus 120 microPET scanner. The xenografts increased in size slightly during this 2 -d interval, from $0.63 \pm$ 0.053 to $0.71 \pm 0.07 \mathrm{~cm}^{3}(12 \%)$ and from $0.61 \pm 0.068$ to $0.69 \pm$ $0.09 \mathrm{~cm}^{3}(11 \%)$ for wild-type and pQCXhNET-IRES-GFP transduced C6 xenografts, respectively. Sequential 15-min list-mode acquisitions were obtained for each animal at 1, 2, 4, 8, 24, 48, and $72 \mathrm{~h}$. A narrow energy window of $420-580 \mathrm{keV}$ and a coincidence timing window of $6 \mathrm{~ns}$ were used. The resulting list-mode data were sorted into 2-dimensional histograms by Fourier rebinning; transverse images were reconstructed by filtered backprojection. The image data were corrected for nonuniformity of scanner response, dead time count losses, and physical decay to the time of 
injection. There was no correction applied for attenuation, scatter, or partial-volume averaging. The measured reconstructed spatial resolution of the Focus 120 is $\sim 1.6-\mathrm{mm}$ FWHM at the center of the field of view.

Region-of-interest (ROI) analysis of the acquired images was performed using ASIPro software (Siemens Medical Solutions USA, Inc.), and the maximum pixel value was recorded for each tissue/organ ROI. A system calibration factor (i.e., $\mathrm{mCi} / \mathrm{mL} / \mathrm{cps} /$ voxel) that was used for analysis derived from reconstructed images of a mouse-size water-filled cylinder containing ${ }^{18} \mathrm{~F}$ and was used to convert the ${ }^{124} \mathrm{I}$ voxel count rates to activity concentrations (after adjustment for the ${ }^{124} \mathrm{I}$ positron branching ratio). The resulting image data were then normalized to the administered activity to parameterize the microPET images in terms of $\% \mathrm{ID} / \mathrm{g}$ (percentage of injected dose per gram of tumor corrected for radioactive decay to the time of injection).

Iodide uptake in thyroid and stomach was not blocked, and radioactivity in these organs reflects radioactive iodide release after the slow catabolism of MIBG. Clearance half-times were calculated from either a single- or a double-exponential fit of the tissue washout profiles: tissue activity $=\mathrm{A}_{0} \cdot \mathrm{e}^{\wedge}\left(-\mathrm{k}_{\mathrm{a}} \cdot \mathrm{t}\right)$ or tissue activity $=$ $\mathrm{A}_{0} \cdot \mathrm{e}^{\wedge}\left(-\mathrm{k}_{\mathrm{a}} \cdot \mathrm{t}\right)+\mathrm{B}_{0} \cdot \mathrm{e}^{\wedge}\left(-\mathrm{k}_{\mathrm{b}} \cdot \mathrm{t}\right)$, respectively. The estimated "\%dose/ $\mathrm{cm}^{3}$ " is given as $\mathrm{A}_{\mathrm{o}}$ or $\mathrm{A}_{\mathrm{o}}+\mathrm{B}_{\mathrm{o}}$, The "\% total radioactivity" was calculated for tissues that required a 2-exponential fit of the washout data and reflects the percentage of radioactivity cleared by the first and second exponentials; this was calculated from $100 \cdot \mathrm{A}_{\mathrm{o}} /\left(\mathrm{A}_{\mathrm{o}}+\right.$ $\left.B_{o}\right)$ and $100 \cdot B_{o} /\left(A_{o}+B_{o}\right)$ for the first and second exponentials, respectively.

\section{Tissue Sampling}

After the last imaging session, $72 \mathrm{~h}$ after ${ }^{124} \mathrm{I}-\mathrm{MIBG}$ injection, all animals were sacrificed; the xenografts as well as various tissues were removed and assayed for radioactivity in a Packard $\gamma$-counter (United Technologies).

\section{Statistics}

Statistical significance of differences between mean values was estimated with Excel (Microsoft) using the independent $t$ test for unequal variances. $P$ values $<0.05$ were considered to be statistically significant.

\section{RESULTS}

\section{Development of hNET Reporter Cell Lines}

To compare the efficiency of imaging the hNET as a reporter gene with ${ }^{123} \mathrm{I}-\mathrm{MIBG} / \mathrm{microSPECT}$ and ${ }^{124} \mathrm{I}-$ MIBG/microPET, a retroviral vector (pQCXhNET-IRESGFP) encoding both hNET and GFP genes was constructed (Fig. 1A) and used to transduce C6, Jurkat, and COS-7 cell lines. COS-7 is a green monkey kidney cell line that has been used in several previous hNET imaging studies (6). To assess the potential for primary $\mathrm{T}$ cells' transduction and imaging with hNET, we choose Jurkat cells (a leukemia T cell line). Unlike primary human T cells, Jurkat cells can be maintained easily in culture in the absence of cytokines. C6 is a rat glioma cell line with good tumorigenic properties and a standard cell line in our laboratory. The pQCXhNETIRES-GFP transduced cells were initially identified by fluorescence microscopy. FACS analyses of the transduced cells demonstrated a difference in transduction efficiency between different cell lines. As expected, COS-7 and C6 had a greater fraction of GFP expression (30\% and $45 \%$, respectively) compared with Jurkat cells (10\%). Gene transfer in Jurkat cells usually results in only a 15\%-20\% transduction efficiency (27). Reporter cells were selected using FACS on the basis of GFP expression. After FACS sorting, $97 \%$ of C6 and COS-7 cells were GFP+; only $76 \%$ of Jurkat cells expressed GFP after the second round of sorting (Fig. 1B).

\section{${ }^{123}$ I-MIBG and ${ }^{124}$ I-MIBG Uptake Study in Wild-Type and hNET Reporter Cells}

The accumulation of iodine-labeled MIBG in tracer quantities was compared in C6/, Jurkat/, and COS-7/ hNET-IRES2-GFP reporter cells and in corresponding wild-type cells. The 3 lines of reporter cells accumulated MIBG rapidly, reaching cell-to-medium ratios $>200$ within $15 \mathrm{~min}$ of incubation. Plateau levels were reached by $90-120 \mathrm{~min}$ and the plateau level varied between the 3 transduced cell lines: COS-7 $\gg \mathrm{C} 6>$ Jurkat (Fig. 2A). Wild-type C6, Jurkat, and Cos-7 cells accumulated MIBG to low levels (cell-to-medium ratio, $\sim 8-10$ ), and these differences were highly significant compared with transduced C6/, Jurkat/, and COS-7/hNET-IRES2-GFP reporter cells $(P<0.00007, P<0.00005$, and $P<0.00001$, respectively). The kinetic parameters derived from a 1-compartment fit of the 0- to 120-min MIBG uptake data (Table 1) indicate that the differences in MIBG uptake primarily reflect differences in $\mathrm{K}_{1}$, as the magnitude of $\mathrm{k}_{2}$ was similar in both wild-type and pQCXhNET-IRES-GFP transduced cells. The relationship between MIBG accumulation $\left(\mathrm{K}_{1}\right)$ and GFP expression (fluorescence intensity) for the 3 transduced cell lines was plotted (Fig. 2B).

To confirm the level of hNET expression in the reporter cells, immunoblot analyses was performed. We found a very high level of hNET expression in transduced COS-7 cells (Fig. 2C, band 4) and less intense bands for transduced C6 and Jurkat cells (Fig. 2C, bands 2 and 6, respectively). No hNET protein bands appeared in wild-type C6 and Jurkat cells (bands 1 and 5, respectively), but weak-intensity bands were identified in COS-7 cells (Fig. 2C, band 3) and SK-N-SH neuroblastoma cells (Fig. 2C, band 7). Both COS-7 and SK-N-SH cells have low levels of endogenous norepinephrine transporter expression (1).

\section{I-MIBG $\boldsymbol{\gamma}$-Camera/microSPECT Imaging}

$\gamma$-Camera (Fig. 3A) and SPECT (Fig. 3B) images of ${ }^{123}$ IMIBG accumulation in C6/hNET-IRES-GFP and C6 wildtype xenografts were obtained at different times (at 4 and $24 \mathrm{~h}$ in cohort 1 and at 4, 24, and $48 \mathrm{~h}$ in cohort 2). As seen in the images, hNET-positive xenografts are better visualized (better signal-to-background) $24 \mathrm{~h}$ after ${ }^{123} \mathrm{I}-\mathrm{MIBG}$ administration compared with visualization of the 4-h images. The 48-h images were somewhat noisy due to isotope decay and a low count rate (3.7 half-lives from time of injection). 


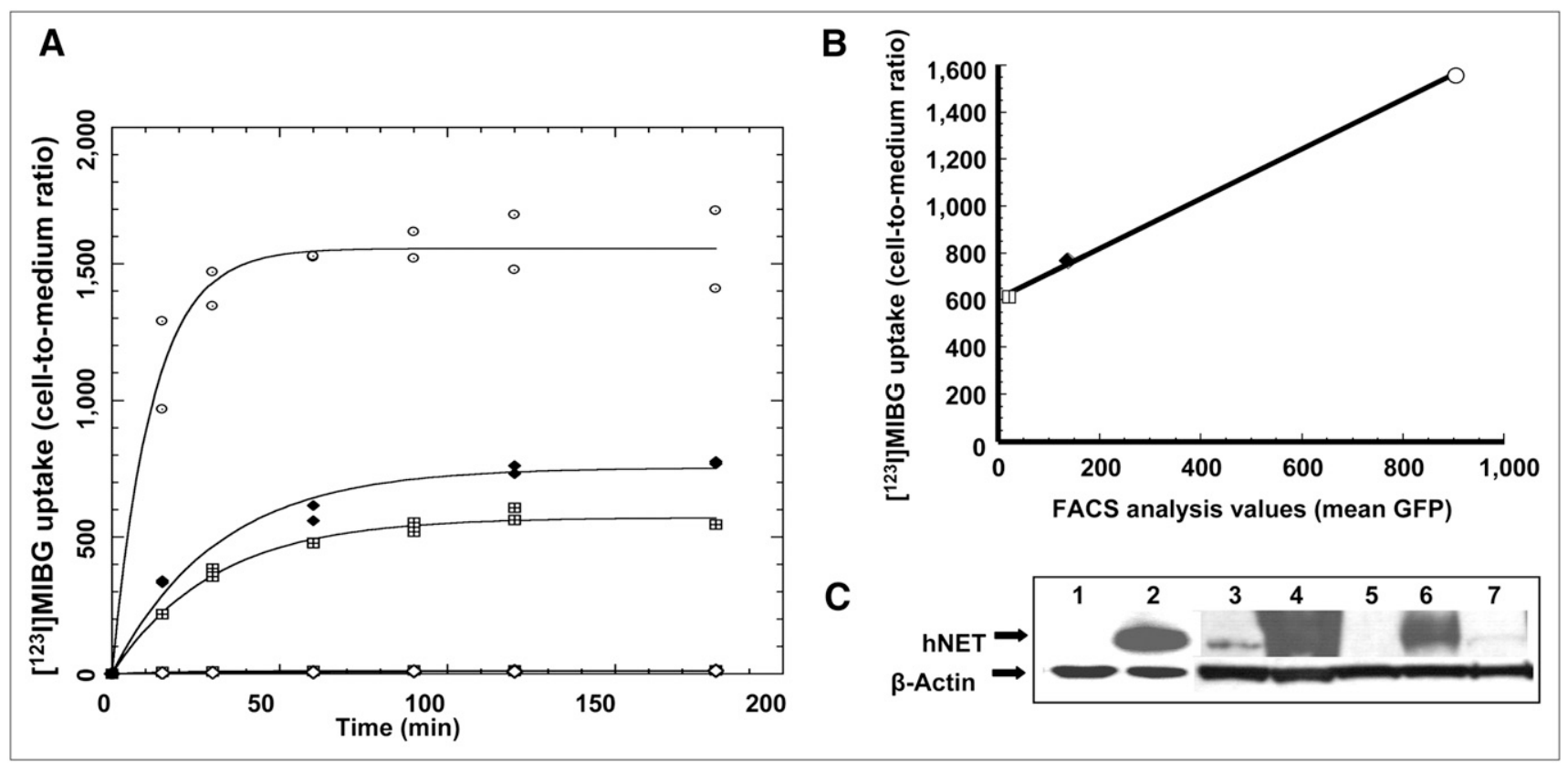

FIGURE 2. In vitro assessment of hNET-IRES-GFP reporter system. (A) Time-activity profiles of ${ }^{123}$ I-MIBG accumulation (mL medium/g cells) in transduced C6 cells (closed diamond), Jurkat cells (open-crossed square), and COS-7 cells (open circle) and in corresponding wild-type cells (open diamond, closed square, and closed circle, respectively). Data were fitted to a 1-compartment model and yielded estimates of $\mathrm{K}_{1}, \mathrm{k}_{2}$, and $\mathrm{V}_{\mathrm{d}}$ (Table 1). (B) ${ }^{123}$ I-MIBG accumulation $\left(\mathrm{V}_{\mathrm{d}}\right.$, Table 1 ) values vs. mean GFP expression values for pQcmv-hNET-IRES-GFP transduced C6 cells (closed diamond), Jurkat cells (open-crossed square), and COS-7 cells (open circle). (C) Western blot analysis for hNET and $\beta$-actin proteins in hNET-IRES-GFP transduced C6 cells (band 2), COS-7 cells (band 4), and Jurkat cells (band 6) and in corresponding wild-type cells (bands 1, 3, and 5, respectively). SK-N-SH neuroblastoma cells served as positive control (band 7).

\section{I-MIBG microPET Imaging}

To further explore the time course of MIBG uptake and clearance, we performed sequential microPET imaging over $72 \mathrm{~h}$ after intravenous injection of ${ }^{124}$ I-MIBG (Fig. 4). High levels of ${ }^{124}$ I-MIBG were seen in the C6/hNET-IRES-GFP xenograft between 4 and $48 \mathrm{~h}$, whereas only background levels of radioactivity were observed in the C6 wild-type xenograft. Initially (at $1 \mathrm{~h}$ ), high levels of radioactivity were also seen in the bladder, kidneys, intestine, liver, and thyroid. The sequential images show retention and a slow washout of radioactivity from the reporter-positive xenograft in comparison with the rapid washout of radioactivity in the wild-type xenograft and other tissues and organs.

\section{Biodistribution Profiles}

Time-activity profiles of ${ }^{124} \mathrm{I}$ radioactivity in the 2 xenografts and in various tissues were generated from data obtained by ROI analysis of the sequential PET images (Fig. 4); the profiles of ${ }^{124} \mathrm{I}-\mathrm{MIBG}$-derived radioactivity in the C6/hNET-IRES-GFP and C6 wild-type xenografts are shown in Figure 5A. Radioactivity in the reportertransduced xenografts increased over the first $8 \mathrm{~h}$ and

TABLE 1

Kinetics of ${ }^{124}$ I-MIBG Uptake in Cell Cultures*

\begin{tabular}{lccrrr}
\hline \multicolumn{1}{c}{ Cell line } & $\mathrm{K}_{1}(\mathrm{~mL} / \mathrm{g} / \mathrm{min})^{\dagger}$ & $\mathrm{k}_{2}\left(\mathrm{~min}^{-1}\right)^{\dagger}$ & $\mathrm{V}_{\mathrm{d}}(\mathrm{mL} / \mathrm{g})^{\dagger}$ & $\mathrm{R}$ & Equilibration t $_{1 / 2}$ (min) $^{\ddagger}$ \\
\hline C6 & $0.14 \pm 0.01$ & $0.021 \pm 0.006$ & $7.6 \pm 0.7$ & 0.970 & 33 \\
Jurkat & $0.60 \pm 0.12$ & $0.052 \pm 0.012$ & $11.6 \pm 0.6$ & 0.946 & 17 \\
COS-7 & $0.43 \pm 0.04$ & $0.042 \pm 0.005$ & $10.4 \pm 0.3$ & 0.975 & 13 \\
C6/hNET-IRES-GFP & $24.1 \pm 2.7$ & $0.032 \pm 0.004$ & $754 \pm 25$ & 0.988 & 22 \\
Jurkat/hNET-IRES-GFP & $18.9 \pm 1.2$ & $0.033 \pm 0.003$ & $572 \pm 13$ & 0.993 & 21 \\
COS-7/hNET-IRES-GFP & $131 \pm 17$ & $0.084 \pm 0.012$ & $1,556 \pm 38$ & 0.973 & 8.3
\end{tabular}

${ }^{*}$ Fit of 0 - to 120 -min values.

${ }^{\dagger}$ Estimated value, \pm SEE.

${ }^{\ddagger}$ Calculated value: $\mathrm{t}_{1 / 2}=\ln 2 / \mathrm{k}_{2}$.

$\mathrm{R}=$ correlation coefficient. 

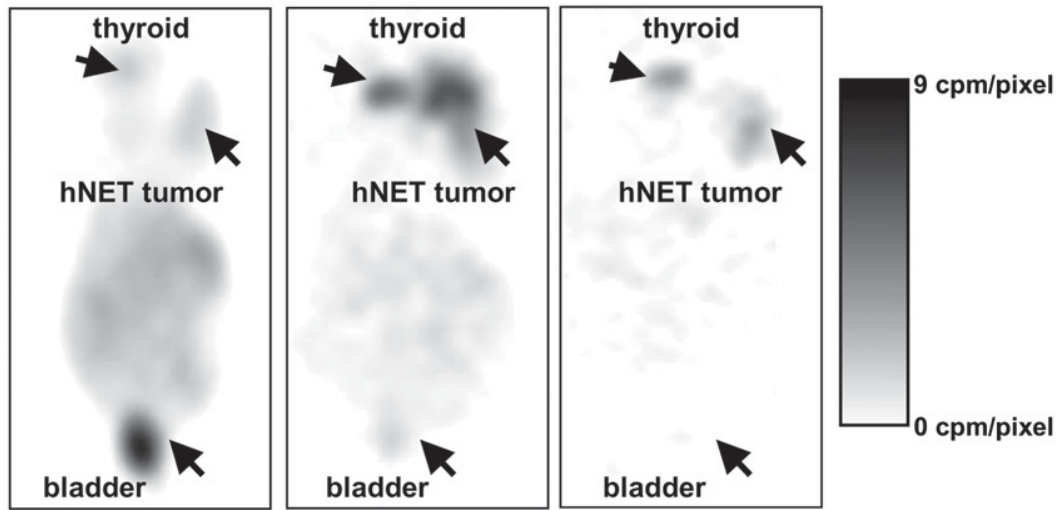

FIGURE 3. $\gamma$-Camera planar (A) and SPECT (B) images of same tumor-bearing mouse at 4,24 , and $48 \mathrm{~h}$ after intravenous injection of $11.1 \mathrm{MBq}(300 \mu \mathrm{Ci})$ of ${ }^{123}$ I-MIBG. Images are coronal views with animal's head at top and tail at bottom of each image. Mouse has C6/hNET-IRESGFP and C6 wild-type xenografts in opposite shoulders. Images are semiquantitative, with planar and SPECT image intensities normalized to maximum count-rate density (i.e., counts per minute [cpm] per pixel and per voxel, respectively) in corresponding 24-h image. Arrows identify the thyroid gland, hNETexpressing xenograft, and bladder.

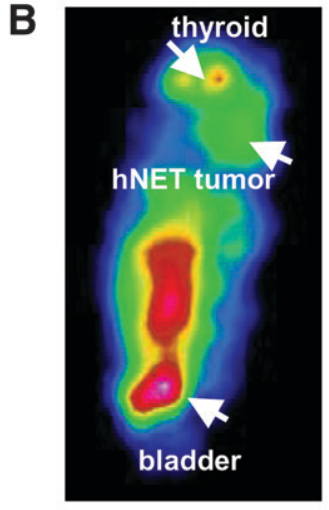

4 hours

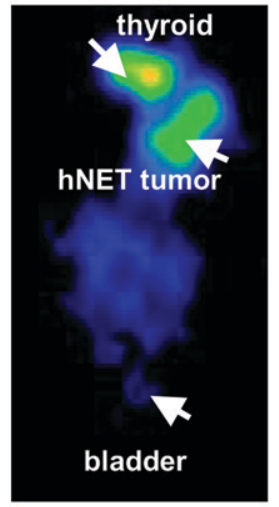

24 hours

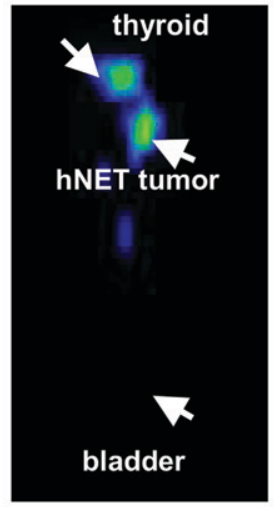

48 hours then slowly washed out with an exponential clearance halftime of $63 \mathrm{~h}$ (Table 2). In contrast, radioactivity in the wildtype xenografts peaked before the initial 1-h imaging session, and an exponential washout with a clearance half-time of $12 \mathrm{~h}$ was observed between 1 and $72 \mathrm{~h}$ (Table 2). Most organs showed a similar radioactivity uptake and washout profile, varying only in magnitude (Table 2). Intestine was an exception in that intestinal radioactivity peaked at $4 \mathrm{~h}$ and then cleared exponentially.

The time course of image contrast, reflected by the xenograft-to-muscle ratio, shows that the C6/hNET-IRESGFP xenograft-to-muscle ratio continues to increase over $72 \mathrm{~h}$ (Fig. 5B). In contrast, the C6-to-muscle radioactivity ratio remained essentially constant over $72 \mathrm{~h}$, with values ranging from 0.9 to 1.6 .

The levels of radioactivity determined by well-counting of postmortem samples were consistent with the imaging results (Table 3). ${ }^{124} \mathrm{I}-\mathrm{MIBG}$-derived radioactivity in the C6/hNET-IRES-GFP tumors $(1.5 \pm 0.3 \% \mathrm{ID} / \mathrm{g})$ was $>100$ fold greater than that in most other sampled tissues and organs. Exceptions included bladder ( $\sim 13$-fold) and thyroid, stomach, and intestine ( $\sim 40$ - to 50-fold).

\section{DISCUSSION}

We confirm the potential of hNET as a useful human reporter gene and demonstrate the advantages of imaging
FIGURE 4. Sequential microPET images of ${ }^{124}$ I-MIBG biodistribution. Sequential coronal $(A)$ and axial $(B)$ images over $72 \mathrm{~h}$ of same mouse bearing C6/ hNET-IRES-GFP and C6 wild-type xenografts in opposite shoulders after intravenous injection of $7.4 \mathrm{MBq}(200 \mu \mathrm{Ci})$ of ${ }^{124} \mathrm{I}-\mathrm{MIBG}$. Arrows identify hNETexpressing xenograft in each image. Max $=$ maximum; Min $=$ minimum.
A
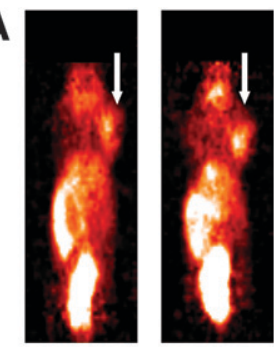

B

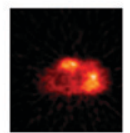

$1 \mathrm{~h}$

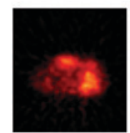

$2 \mathrm{~h}$

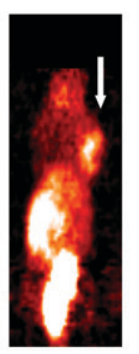

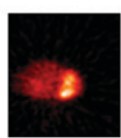

$4 \mathrm{~h}$
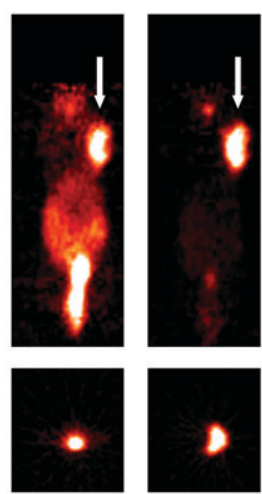

$8 \mathrm{~h}$

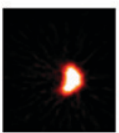

$24 \mathrm{~h}$

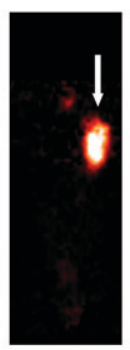

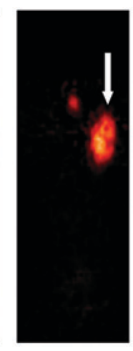

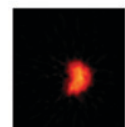

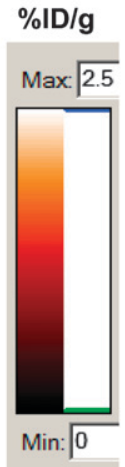

$72 \mathrm{~h}$

$48 \mathrm{~h}$

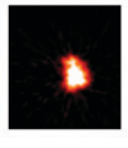




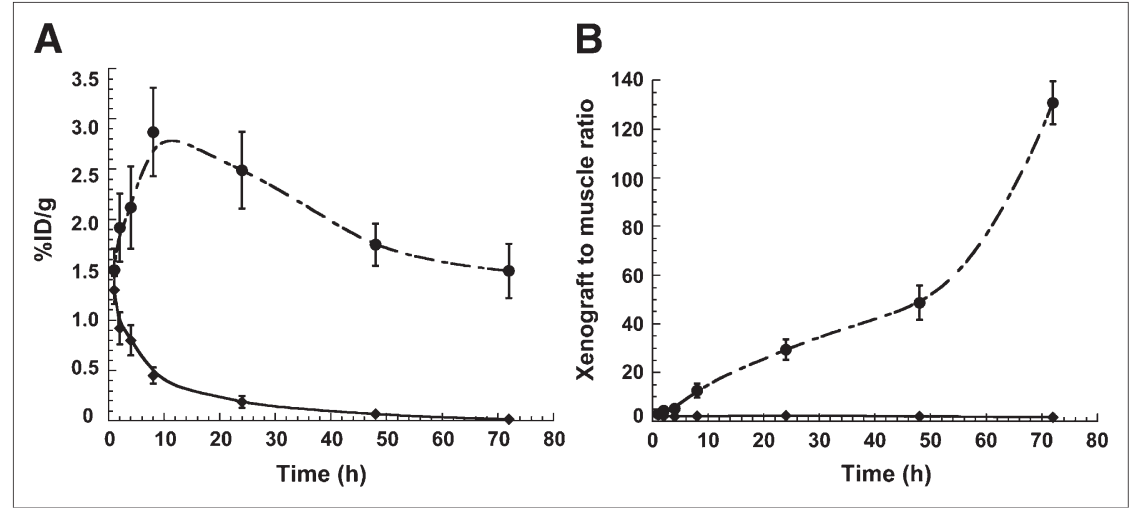

FIGURE 5. Time-activity profiles of ${ }^{124} \mid-$ MIBG accumulation. (A) Tissue radioactivity values $(\% \mathrm{ID} / \mathrm{g})$ were determined from sequential microPET images (see Fig. 4), and time-activity profiles for C6/ hNET-IRES-GFP (circles) and C6 wildtype xenografts (diamonds) are shown. (B) Xenograft-to-muscle profiles are also shown. Values are mean $\pm \mathrm{SD} ; n=10$. with ${ }^{124} \mathrm{I}-\mathrm{MIBG}$ and PET. The hNET immunoblot, GFPFACS, and in vitro MIBG uptake studies in 3 different cell lines demonstrate cell-specific differences in transduction/ expression efficiency $(\mathrm{Cos}-7 \gg \mathrm{C} 6>$ Jurkat). These differences appear to be more related to transcriptional expression than to posttranslational effects or to differences in the insertion of hNET into the cell membrane or transport function, as a relatively constant relationship was maintained between the level of GFP expression and MIBG accumulation (Fig. 2B). The kinetic analysis was consistent with a 1-compartment (cell) model, where the equilibrium accumulation level $\left(\mathrm{V}_{\mathrm{d}}\right)$ of MIBG was determined primarily by the influx rate $\left(\mathrm{K}_{1}\right)$. Efflux was similar between cell lines and between transduced and wild-type cells; the mean equilibration half-time for transduced and wild-type cells calculated from the efflux values was $17 \pm 8$ and $21 \pm 11$ min, respectively. The kinetic data suggest that efflux of MIBG from the cells is "passive" and independent of transporter expression levels.

\section{Imaging hNET Expression}

The in vivo imaging studies demonstrated better image quality with ${ }^{124} \mathrm{I}-\mathrm{MIBG}$ and PET compared with ${ }^{123} \mathrm{I}-$ MIBG and SPECT, particularly at the later time points. This better image quality was observed despite the lower specific activity of ${ }^{124}$ I-MIBG compared with that of ${ }^{123} \mathrm{I}-$ MIBG. Previous studies have shown that higher levels (\% ID/g or standardized uptake value) of ${ }^{123}$ I-MIBG were accumulated by hNET-expressing tissues using a radiopharmaceutical with very high specific activity compared with that measured using a commercially available product with lower specific activity $(28,29)$. However, image quality (transduced tumor-to-background) was not appreciably different, due to the higher surrounding tissue (background) activity observed with high specific activity ${ }^{123}$ I-MIBG SPECT.

High levels of MIBG-derived radioactivity were measured in the transduced xenografts; radioactivity levels peaked at $8 \mathrm{~h}$ and then cleared in an exponential manner. A single 24-h ${ }^{123}$ I-MIBG uptake value in nude mice bearing a human neuroblastoma (PC12) or a bovine bNET-transduced (A431NET) cell line/xenograft has been reported, and the values $(1.3 \pm 0.3 \% \mathrm{ID} / \mathrm{g}$ and $2.6 \pm 0.9 \% \mathrm{ID} / \mathrm{g}$, respectively) were similar to that measured here for $\mathrm{C} 6 /$ hNET-IRES-GFP xenografts $(2.2 \pm 0.9 \%$ ID/g) (5). The wild-type A431 xenograft and muscle values (0.08 and 0.11 $\% \mathrm{ID} / \mathrm{g})$ were also quite similar to that measured in this study (0.09 and $0.19 \% \mathrm{ID} / \mathrm{g}$, respectively). Given the difference between tissue sampling and PET measures, these studies demonstrate that very high NET-transduced tissueto-muscle ratios can be achieved using radiolabeled MIBG

TABLE 2

Clearance of ${ }^{124}$ I-MIBG-Derived Radioactivity

\begin{tabular}{|c|c|c|c|}
\hline Tissue or organ & $\%$ dose $/ \mathrm{cm}^{3 *}$ & Clearance half-time $(h)^{\dagger}$ & $\%$ of total radioactivity \\
\hline C6/hNET-IRES-GFP xenograft & $3.2 \pm 0.2$ & $63 \pm 6$ & \\
\hline C6 wild-type xenograft & $0.99 \pm 0.08$ & $12 \pm 1$ & \\
\hline Muscle & $0.42 \pm 0.22$ & $13 \pm 4$ & \\
\hline Heart & $2.0 \pm 0.5$ & $3.6 \pm 0.4 / 19 \pm 2^{\ddagger}$ & $48 / 52^{\ddagger}$ \\
\hline Thyroid & $2.4 \pm 1.2$ & $21 \pm 10$ & \\
\hline Abdomen & 9.4 & $3.4 \pm 0.3 / 29 \pm 15^{\ddagger}$ & $95 / 5^{\ddagger}$ \\
\hline Kidney & 1.1 & $13 \pm 1$ & \\
\hline Bladder & $47 \pm 21$ & $2.6 \pm 0.9 / 19 \pm 7^{\ddagger}$ & $97 / 3^{\ddagger}$ \\
\hline \multicolumn{4}{|l|}{$\begin{array}{l}{ }^{*} \text { Estimated value a } \mathrm{t}=0, \pm \mathrm{SEE} . \\
{ }^{\dagger} \text { Estimated value, } \pm \mathrm{SEE} .\end{array}$} \\
\hline
\end{tabular}


TABLE 3

${ }^{124}$ I-MIBG Biodistribution: Comparison of Radioactivity Levels Measured in $\gamma$-Well Counter at 73 Hours After Injection with ROI Analysis Performed at 72 Hours After Injection

\begin{tabular}{|c|c|c|c|}
\hline \multirow[b]{2}{*}{ Tissue } & \multicolumn{2}{|c|}{ Tissue samples } & \multirow{2}{*}{$\begin{array}{l}\text { Image ROI analysis } \\
\% \text { ID/mL (72 h) }\end{array}$} \\
\hline & $\%$ ID/g (73 h) & Tissue-to-muscle ratio $(73 \mathrm{~h})^{\star}$ & \\
\hline C6/hNET-IRES-GFP xenograft & $1.5 \pm 0.3$ & $293 \pm 48$ & $1.5 \pm 0.3$ \\
\hline C6 wild-type xenograft & $0.0037 \pm 0.0021$ & $0.71 \pm 0.19$ & $0.018 \pm 0.006$ \\
\hline Brain & $0.0014 \pm 0.0004$ & $0.22 \pm 0.04$ & \\
\hline Heart & $0.018 \pm 0.005$ & $2.7 \pm 0.5$ & $0.09 \pm 0.03$ \\
\hline Lung & $0.011 \pm 0.005$ & $2.4 \pm 0.3$ & \\
\hline Thyroid & $0.033 \pm 0.024$ & $6.2 \pm 1.2$ & $0.24 \pm 0.16$ \\
\hline Liver & $0.017 \pm 0.004$ & $2.5 \pm 0.6$ & \\
\hline Kidney & $0.016 \pm 0.002$ & $1.5 \pm 0.3$ & $0.045 \pm 0.004$ \\
\hline Adrenal glands & $0.014 \pm 0.016$ & $2.5 \pm 0.3$ & \\
\hline Intestine & $0.028 \pm 0.017$ & $4.2 \pm 0.8$ & $0.055 \pm 0.033$ \\
\hline Intestinal contents & $0.026 \pm 0.018$ & $4.1 \pm 0.6$ & \\
\hline Stomach & $0.036 \pm 0.024$ & $6.2 \pm 1.5$ & \\
\hline Stomach contents & $0.016 \pm 0.024$ & $2.5 \pm 0.5$ & \\
\hline Bladder & $0.12 \pm 0.12$ & $22 \pm 3$ & $0.11 \pm 0.034$ \\
\hline Muscle & $0.0054 \pm 0.002$ & 1 & \\
\hline $\begin{array}{l}\text { Values are mean } \pm \mathrm{SD}, n=10 \text {. } \\
{ }^{*} \text { Tissue-to-muscle ratio. }\end{array}$ & & & \\
\hline
\end{tabular}

and a "late imaging" paradigm. At $24 \mathrm{~h}$, this ratio was 17:1, 24:1, and 30:1 for PC12, A431NET, and C6/hNET-IRES-GFP xenografts, respectively. Although ${ }^{124} \mathrm{I}-\mathrm{MIBG}$ was slowly washing out of the transduced xenograft, imaging at later times (48 and $72 \mathrm{~h}$ ) resulted in substantially higher C6/hNETIRES-GFP xenograft-to-muscle ratios (49:1 and 130:1, respectively) (Fig. 5B) because the washout and clearance of radioactivity from systemic tissues and the nontransduced xenograft was $\sim 5$-fold more rapid (Fig. 5A).

The 2- and 4-h radioactivity values for hNET-transduced xenografts in rats reported by Altmann et al. (4) were similar to that observed in our study in mice, whereas the 24- and 48-h values in Altman et al. (4) were one fifth to one tenth of that reported here. The lower radioactivity values in the Altman et al. (4) study suggest a more rapid washout and clearance of ${ }^{131}$ I-MIBG radioactivity in their animals and may reflect a species difference between rats and mice. The estimated halftime of radioactivity clearance from their hNET-transduced xenografts can be calculated from the tissue-sampling data presented (1); a $\mathrm{t}_{1 / 2}$ of $11 \pm 1 \mathrm{~h}$ was calculated and this is considerably shorter than the $63 \pm 6 \mathrm{~h}$ obtained for C6 hNETIRES-GFP xenografts in this study. Surprisingly, the calculated half-time of radioactivity clearance from wild-type xenografts in the Altman et al. study (4) was $13 \pm 2 \mathrm{~h}$ and very similar to that for their hNET-transduced xenografts. In contrast, the clearance of ${ }^{124} \mathrm{I}-\mathrm{MIBG}$ from the C6/hNETIRES-GFP xenografts in this study was significantly slower, $\sim 5$-fold, than in C6 wild-type xenografts and most host tissues (average, $13 \pm 3 \mathrm{~h}$; Table 2). We suggest that the slow clearance of ${ }^{124}$ I-MIBG from C6/hNET-IRES-GFP xenografts reported here is not due to a difference in efflux rate between transduced and wild-type cells, as the in vitro studies showed similar MIBG efflux rate constants in wild-type and transduced cells. Rather, this difference more likely reflects rapid, local reuptake of ${ }^{124} \mathrm{I}-\mathrm{MIBG}$ in the transduced xenografts in comparison with that in normal host tissues and the wild-type xenografts.

Other radiolabeled ligands have been developed previously to image NET function and study noradrenergic innervation and activity, particularly in the heart and brain. Most success has been associated with imaging sympathetic enervation in normal and abnormal cardiac states, including diabetes, cardiomyopathy, congestive heart failure, myocardial infarction, and after heart transplantation using ${ }^{11} \mathrm{C}$ meta-hydroxyephedrine (HED), ${ }^{11} \mathrm{C}$-epinedrine (EPI) and PET (30,31). ${ }^{11} \mathrm{C}-\mathrm{HED}$ and PET has been shown to have certain advantages for imaging neuroendocrine tumors (neuroblastoma, pheochromocytoma, gangliogliomas, etc.) compared with ${ }^{123}$ I-MIBG and SPECT due to differences in imaging resolution and sensitivity between PET and SPECT tomographs, as well as the differences in half-life of the PET and SPECT radionuclides (32-34). Only limited success has been achieved in developing novel ligands for imaging NET transporter function in the brain. This has been largely due to the blood-brain barrier and hydrophilicity of established ligands such as MIBG and HED; detailed discussions of the relevant issues are presented in a recent review (12).

Few direct comparisons between ${ }^{11} \mathrm{C}-\mathrm{HED}$ and ${ }^{123} \mathrm{I}-\mathrm{MIBG}$ imaging of neuroendocrine tumors have been performed. In a recent study of 19 consecutive patients, ${ }^{11} \mathrm{C}-\mathrm{HED}$ PET/CT (low-dose CT) studies were compared with attenuationcorrected ${ }^{123}$ I-MIBG SPECT/CT scans obtained 5- to $\sim 20$ min and $24 \mathrm{~h}$ after tracer administration, respectively (32). ${ }^{11} \mathrm{C}-\mathrm{HED}$ PET/CT detected 80 of 81 tumor lesions and 
${ }^{123}$ I-MIBG SPECT/CT detected 75 of 81 lesions; there were no false-positive lesions with either tracer. Lesion-to-background contrast varied; ${ }^{11} \mathrm{C}-\mathrm{HED}$ PET displayed greater contrast than ${ }^{123}$ I-MIBG SPECT in 26 lesions, whereas the reverse was observed in 16 lesions (the remaining 39 lesions were judged to have equal contrast). In a recent study of pheochromocytoma, ${ }^{11} \mathrm{C}$-HED PET was found to be superior to ${ }^{131} \mathrm{I}-\mathrm{MIBG}$ planar scintigraphy in detecting tumor (35). However, no comparative ${ }^{11} \mathrm{C}$-HED PET versus ${ }^{124} \mathrm{I}-\mathrm{MIBG}$ PET studies have yet been reported. The major potential advantages of ${ }^{124} \mathrm{I}-\mathrm{MIBG}$ PET are low background and high contrast using a "late imaging" paradigm, whereas ${ }^{11} \mathrm{C}-\mathrm{HED}$ PET will have dosimetry and count-rate advantages that will permit repeated imaging studies. A comparison of recently published ${ }^{11} \mathrm{C}$-HED microPET images of mice (6) with the ${ }^{124}$ I-MIBG microPET images of mice reported here clearly illustrates the differences in background radioactivity and contrast that can be achieved with a "late imaging" paradigm (Figs. 4 and 5). Nevertheless, each of these 2 ligands would be expected to have specific applications in hNET reporter studies in patients and will likely be used in parallel.

\section{Regulation of NET Expression}

The regulation of NET expression and function is complex and involves several cellular systems. This includes alternative splicing (1), N-glycosylation of the TM3 and TM4 extracellular loop that alters intracellular trafficking and transmembrane expression (36,37), and several intracellular signaling pathways and molecules that are involved in phosphorylation of NET, including cyclic adenosine monophosphate (cAMP), protein kinases A and C (38) that all impact on and regulate cell-surface expression and function. There are 3 known C-terminal variants of the hNET. Although no differences were observed among the NET isoforms with respect to the Michaelis-Menten constant $\left(\mathrm{K}_{\mathrm{m}}\right)$ for uptake of ${ }^{3} \mathrm{H}$-norepinephrine and the dissociation constant $\left(\mathrm{K}_{\mathrm{D}}\right)$ for binding of ${ }^{3} \mathrm{H}$-nisoxetine, there was a marked decrease in the maximum velocity $\left(\mathrm{V}_{\max }\right)$ and maximum binding capacity $\left(\mathrm{B}_{\max }\right)$ for the spliced isoforms (39). The differences in $\mathrm{V}_{\max }$ and $\mathrm{B}_{\max }$ were shown to be strongly correlated with the cell-surface expression of the hNET isoforms. The decrease in cell-surface expression of the transporter in the 2 truncated isoforms was considered to be due to the lack of 3 amino acids (leucine, alanine, and isoleucine) at the C-terminal end. Thus, only the dominant, nontruncated hNET isoform is optimal for reporter gene imaging studies.

Concern has been raised previously about the potential signaling and functional effects of using monoamine receptors as reporter genes. This concern prompted the group at the University of California at Los Angeles to generate a signaling-inert mutant dopamine 2 receptor (D2R) for their reporter gene studies (40). Chronic activation of transduced wild-type D2R by endogenous monoamines could result in G-protein- mediated inhibition of adenylyl cyclase activity and chronic reduction of cAMP levels. Because these effects could alter several other signaling pathways and biologic function of the transduced cells and tissue, they developed and studied several mutant D2Rs. They showed that the D2 $R_{80 \mathrm{~A}}$ variant has similar in vitro ${ }^{3} \mathrm{H}$-spiperone binding parameters compared with wild-type D2R, but there was complete uncoupling of ligand binding from activation of the G-protein system. Stimulation of D2R $\mathrm{R}_{80 \mathrm{~A}}$-transduced cells with dopamine had no effect on cAMP levels.

Although hNET is not a receptor, it remains to be shown whether transducing cells with the hNET gene and cellsurface expression of the transporter will result in significant changes in specific signaling molecules and pathways that alter the biologic state of the transduced cells and tissue. We did not observe any difference in growth rate of wild-type C6 and transduced C6/hNET-IRES-GFP xenografts in nude mice. However, it was recently shown that norepinephrine can induce increases in brain-derived neurotrophic factor (BDNF) and phosphorylated cephalochordate neurotrophin receptor (Trk) in isolated embryonic hippocampal neurons, and these increases can be prevented by ERK (external regulated kinase) and PI-3K (PI-kinase) inhibitors. These results indicate that norepinephrine-induced BDNF expression follows a cyclic pathway, suggestive of a positive feedback loop, and provides an in vitro model of intracellular signaling mechanisms activated by norepinephrine, via ligand-G-protein-coupled receptor-to-BDNF receptor tyrosine kinase transactivation. The similarity to the dopamine G-protein-coupled D2R receptor-to-adenylyl cyclase system described above is noted. These are important issues and further studies addressing them need to be performed.

Cell-specific functionality may be important for the general application of hNET as a reporter gene, as the cellsurface expression and function of hNET are complex and highly regulated. Issues related to alternative splicing during transcription, N-glycosylation of specific extracellular, modulation by endogenous or induced protein kinase $\mathrm{C}$ pathway activity, and the effects of circulating norepinephrine (and other monamines) need to be considered. These processes could have a significant effect on the magnitude of radiolabeled probe accumulation and the imaging readout of the hNET reporter in different transduced cells and tissue. Further studies will have to be performed to determine the magnitude and significance of these potential limitations.

\section{CONCLUSION}

These studies demonstrate the potential for a wider application of hNET reporter imaging with ${ }^{124} \mathrm{I}-\mathrm{MIBG}$ and PET and for the future translation to patient studies using radiopharmaceuticals that are currently available for both SPECT and PET.

\section{ACKNOWLEDGMENTS}

We thank Dr. Uwe Haberkorn for kindly providing hNET plasmid; Memorial Sloan-Kettering Cancer Center 
Radiopharmacy, Cyclotron, Flow Cytometry, and Small Animals Imaging facilities; as well as Nagavarakishore Pillarsetty, PhD, and Rashid E. Ghani, RPh, MBA, for assistance with data collection and extensive discussions. This work was supported by the following grants: NIH grant P50-CA84638, NIH grant R24-CA98023, NCI Center Support Core grant P30-CA-08748, and U.S. Department of Energy grant DE-FG02-86ER60407.

\section{REFERENCES}

1. Pacholczyk T, Blakely R, Amara S. Expression cloning of a cocaine and antidepressant-sensitive human noradrenaline transporter. Nature. 1991;350: 350-354.

2. Porzgen P, Bonisch H, Bruss M. Molecular cloning and organization of the coding region of the human norepinephrine transporter gene. Biochem Biophys Res Commun. 1995;215:1145-1150.

3. Axelrod J, Kopin IJ. The uptake, storage, release, and metabolism of noradrenaline in sympathetic nerves. Prog Brain Res. 1969;31:21-32.

4. Altmann A, Kissel M, Zitzmann S, et al. Increased MIBG uptake after transfer of the human norepinephrine transporter gene in rat hepatoma. J Nucl Med. 2003; 44:973-980.

5. Anton M, Wagner B, Haubner R, et al. Use of the norepinephrine transporter as a reporter gene for non-invasive imaging of genetically modified cells. J Gene Med. 2004;6:119-126.

6. Buursma AR, Beerens AM, de Vries EF, et al. The human norepinephrine transporter in combination with ${ }^{11} \mathrm{C}$-m-hydroxyephedrine as a reporter gene/ reporter probe for PET of gene therapy. J Nucl Med. 2005;46:2068-2075.

7. Ezziddin S, Logvinski T, Yong-Hing C, et al. Factors predicting tracer uptake in somatostatin receptor and MIBG scintigraphy of metastatic gastroenteropancreatic neuroendocrine tumors. J Nucl Med. 2006;47:223-233.

8. Wieland DM, Brown LE, Rogers WL, et al. Myocardial imaging with a radioiodinated norepinephrine analog. J Nucl Med. 1981;22:22-31.

9. Shulkin BL, Shapiro B, Tobes MC, et al. Iodine-123-4-amino-3-iodobenzylguanidine, a new sympathoadrenal imaging agent: comparison with iodine-123 metaiodobenzylguanidine. J Nucl Med. 1986;27:1138-1142.

10. Glowniak JV, Kilty JE, Amara SG, et al. Evaluation of metaiodobenzylguanidine uptake by the norepinephrine, dopamine and serotonin transporters. J Nucl Med. 1993;34:1140-1146.

11. Schwaiger M, Kalff V, Rosenspire K, et al. Noninvasive evaluation of sympathetic nervous system in human heart by positron emission tomography. Circulation. 1990;82:457-464.

12. Ding YS, Fowler J. New-generation radiotracers for $\mathrm{nAChR}$ and NET. Nucl Med Biol. 2005;32:707-718.

13. Tjuvajev JG, Stockhammer G, Desai R, et al. Imaging the expression of transfected genes in vivo. Cancer Res. 1995;55:6126-6132.

14. Jacobs A, Voges J, Reszka R, et al. Positron-emission tomography of vectormediated gene expression in gene therapy for gliomas. Lancet. 2001;358:727729.

15. Gambhir SS, Bauer E, Black ME, et al. A mutant herpes simplex virus type 1 thymidine kinase reporter gene shows improved sensitivity for imaging reporter gene expression with positron emission tomography. Proc Natl Acad Sci U S A. 2000;97:2785-2790.

16. Penuelas I, Mazzolini G, Boan JF, et al. Positron emission tomography imaging of adenoviral-mediated transgene expression in liver cancer patients. Gastroenterology. 2005;128:1787-1795.

17. Riddel SR, Elliott M, Lewinsohn DA, et al. T-cell mediated rejection of genemodified HIV-specific cytotoxic T lymphocytes in HIV-infected patients. Nat Med. 1996;2:216-223.
18. Haberkorn U, Henze M, Altmann A, et al. Transfer of the human NaI symporter gene enhances iodide uptake in hepatoma cells. J Nucl Med. 2001;42: $317-325$.

19. Rogers BE, McLean SF, Kirkman RL, et al. In vivo localization of [ $\left.{ }^{111} \mathrm{In}\right]-\mathrm{DTPA}-$ D-Phe1-octreotide to human ovarian tumor xenografts induced to express the somatostatin receptor subtype 2 using an adenoviral vector. Clin Cancer Res. 1999;5:383-393.

20. MacLaren DC, Gambhir SS, Satyamurthy N, et al. Repetitive, non-invasive imaging of the dopamine D2 receptor as a reporter gene in living animals. Gene Ther. 1999;6:785-791.

21. Tazebay UH, Wapnir IL, Levy O, et al. The mammary gland iodide transporter is expressed during lactation and in breast cancer. Nat Med. 2000;6:871-878.

22. Barrio JR, Satyamurthy N, Huang SC, et al. $3-\left(2^{\prime}-\left[{ }^{18}\right.\right.$ F $]$ Fluoroethyl $)$ spiperone in vivo biochemical and kinetic characterization in rodents, non-human primates, and humans. J Cereb Blood Flow Metab. 1989;9:830-839.

23. Che J, Doubrovin M, Serganova I, et al. hNIS-IRES-eGFP dual reporter gene imaging. Mol Imaging. 2005;4:128-136.

24. Serganova I, Doubrovin M, Vider J, et al. Molecular imaging of temporal dynamics and spatial heterogeneity of hypoxia-inducible factor-1 signal transduction activity in tumors in living mice. Cancer Res. 2004;64:6101-6108.

25. Ponomarev V, Doubrovin M, Serganova I, et al. Cytoplasmically retargeted HSV1-tk/GFP reporter gene mutants for optimization of noninvasive moleculargenetic imaging. Neoplasia. 2003;5:245-254.

26. Eersels J, Herscheid J. Manufacturing I-123-labelled radiopharmaceuticals: pitfalls and solutions. J Labelled Compds Radiopharm. 2005;48:241-257.

27. Dardalhon V, Noraz N, Pollok K, et al. Green fluorescent protein as a selectable marker of fibronectin-facilitated retroviral gene transfer in primary human $\mathrm{T}$ lymphocytes. Hum Gene Ther. 1999;10:5-14.

28. Farahati J, Bier D, Scheubeck M, et al. Effect of specific activity on cardiac uptake of iodine-123-MIBG. J Nucl Med. 1997;38:447-451.

29. Verberne HJ, de Bruin K, Habraken JB, et al. No-carrier-added versus carrieradded ${ }^{123}$ I-metaiodobenzylguanidine for the assessment of cardiac sympathetic nerve activity. Eur J Nucl Med Mol Imaging. 2006;33:483-490.

30. Pirich C, Schwaiger M. The clinical role of positron emission tomography in management of the cardiac patient. Rev Port Cardiol. 2000;19(suppl 1):I89-100.

31. Munch G, Nguyen NT, Nekolla S, et al. Evaluation of sympathetic nerve terminals with $\left[{ }^{11} \mathrm{C}\right]$ epinephrine and $\left[{ }^{11} \mathrm{C}\right]$ hydroxyephedrine and positron emission tomography. Circulation. 2000;101:516-523.

32. Shulkin BL, Wieland DM, Baro ME, et al. PET hydroxyephedrine imaging of neuroblastoma. J Nucl Med. 1996;37:16-21.

33. Mann GN, Link JM, Pham P, et al. $\left[{ }^{11} \mathrm{C}\right]$ Metahydroxyephedrine and $\left[{ }^{18} \mathrm{~F}\right]$ fluorodeoxyglucose positron emission tomography improve clinical decision making in suspected pheochromocytoma. Ann Surg Oncol. 2006;13:187-197.

34. Rufini V, Calcagni ML, Baum RP. Imaging of neuroendocrine tumors. Semin Nucl Med. 2006;36:228-247.

35. Franzius C, Hermann K, Weckesser M, et al. Whole-body PET/CT with ${ }^{11} \mathrm{C}$ meta-hydroxyephedrine in tumors of the sympathetic nervous system: feasibility study and comparison with ${ }^{123}$ I-MIBG SPECT/CT. J Nucl Med. 2006;47:16351642 .

36. Melikian HE, Ramamoorthy S, Tate CG, et al. Inability to N-glycosylate the human norepinephrine transporter reduces protein stability, surface trafficking, and transport activity but not ligand recognition. Mol Pharmacol. 1996;50:266-276.

37. Amara SG. Neurotransmitter transporters: new insights into structure, function and pharmacology. Rev Bras Biol. 1996;56:5-19.

38. Mandela P, Ordway GA. The norepinephrine transporter and its regulation. J Neurochem. 2006;97:310-333.

39. King VL, Dwoskin LP, Cassis LA. Cold exposure regulates the norepinephrine uptake transporter in rat brown adipose tissue. Am J Physiol. 1999;276:143-151.

40. Liang Q, Phelps MP, Gambhir SS, et al. Noninvasive, quantitative imaging in living animals of a mutant dopamine D2 receptor reporter gene in which ligand binding is uncoupled from signal transduction. Gene Ther. 2001;8:14901498 . 